\title{
Ceria-Zirconia Particles Wrapped in a 2D Carbon Envelope: Improved Low-Temperature Oxygen Transfer and Oxidation Activity
}

\author{
Eleonora Aneggi, Veronica Rico-Perez, Carla de Leitenburg, Stefano Maschio, Lluís Soler, \\ Jordi Llorca,* and Alessandro Trovarelli*
}

\begin{abstract}
Engineering the interface between different components of heterogeneous catalysts at nanometer level can radically alter their performances. This is particularly true for ceria-based catalysts where the interactions are critical for obtaining materials with enhanced properties. Here we show that mechanical contact achieved by high-energy milling of $\mathrm{CeO}_{2}-\mathrm{ZrO}_{2}$ powders and carbon soot results in the formation of a core of oxide particles wrapped in a thin carbon envelope. This $2 D$ nanoscale carbon arrangement greatly increases the number and quality of contact points between the oxide and carbon. Consequently, the temperatures of activation and transfer of the oxygen in ceria are shifted to exceptionally low temperatures and the soot combustion rate is boosted. The study confirms the importance of the redox behavior of ceriazirconia particles in the mechanism of soot oxidation and shows that the organization of contact points at the nanoscale can significantly modify the reactivity resulting in unexpected properties and functionalities.
\end{abstract}

$T_{\text {he development of robust carbon soot combustion catalysts }}$ is one of the key points in realizing a sustainable chain of reactions to remove noxious compounds $\left(\mathrm{NO}_{\mathrm{X}}, \mathrm{VOC}\right.$, and soot) from diesel engines. In this regard, $\mathrm{CeO}_{2}$-based materials play a major role as documented by the great variety of formulations that have been tested over the last few years. ${ }^{[1]}$ In particular, ceria-rich $\mathrm{CeZrO}$ solid solutions have been shown to offer good textural and redox behavior; this, coupled with their thermal and structural stability, results in optimal soot oxidation catalysts. ${ }^{[2]}$ In parallel with the

[*] Dr. E. Aneggi, Dr. V. Rico-Perez, Prof. C. de Leitenburg,

Prof. S. Maschio, Prof. A. Trovarelli

Department of Chemistry, Physics, and Environment

University of Udine

Via del Cotonificio 108, IT-33100 Udine (Italy)

E-mail: trovarelli@uniud.it

Dr. L. Soler, Prof. J. Llorca

Institut de Tècniques Energètiques and

Centre for Research in Nanoengineering

Universitat Politècnica de Catalunya

Diagonal 647, 08028 Barcelona (Spain)

E-mail: jordi.llorca@upc.edu

(i) Supporting information and ORCID(s) from the author(s) for this article are available on the WWWW under http://dx.doi.org/10.1002/ anie.201507839.

of (C) 2015 The Authors. Published by Wiley-VCH Verlag GmbH \& Co. $\mathrm{KGaA}$. This is an open access article under the terms of the Creative Commons Attribution Non-Commercial License, which permits use, distribution and reproduction in any medium, provided the original work is properly cited and is not used for commercial purposes. development of novel compositions, the understanding of how ceria works in this complex and somewhat unusual environment, where both catalyst and one reagent are in solid phase, has considerably progressed. The active ingredients for carbon oxidation are the so-called "active oxygen species", highly reactive species generated by exchanging ceria oxygen with gas phase oxygen through vacancy formation. It is the morphology of catalyst-carbon contact points/interface that make possible a rapid transfer of these surface oxygen species (reverse spillover) over carbon soot for oxidation in a manner similar to that described for metal nanoparticles in contact with ceria surfaces, ${ }^{[3]}$ thus highlighting the importance of catalyst-carbon contact in promoting soot oxidation activity. With the aim of better understanding this complex matter we report here for the first time the creation of a nanoscale soot/ ceria-zirconia composite by a mechanical process, where a nanometer-thin porous carbon envelope covers ceriazirconia particles creating a "supertight" catalyst-soot contact which dramatically boosts soot oxidation rates by activating oxygen transfer at very low temperatures compared to the most active catalysts available. This observation confirms the important function of redox chemistry of ceria in generating active oxygen species which play a pivotal role in reducing the soot oxidation temperature, and provides an additional piece of information for understanding at nanoscale level the influence of the catalyst-carbon contact morphology in the soot combustion reaction.

A sample of ceria-zirconia particles of composition $\mathrm{Ce}_{0.8} \mathrm{Zr}_{0.2} \mathrm{O}_{2}$ (CZ) prepared by co-precipitation was investigated in this study. The material crystallizes in a cubic fluorite structure, as expected for the $\mathrm{Ce} / \mathrm{Zr}$ ratio:; ${ }^{[4]}$ the redox behavior, as shown by temperature-programed reduction (Figure S1) is characterized by a single broad peak of hydrogen consumption in the temperature range of 300$650^{\circ} \mathrm{C}$, with a total $\mathrm{H}_{2}$ uptake of $1191 \mu \mathrm{molg}{ }^{-1}$, corresponding to a $\mathrm{Ce}^{4+} / \mathrm{Ce}^{3+}$ reduction degree of about $40 \%$. The conventional mixing of ceria-zirconia particles with carbon soot (weight ratio catalyst:soot of 20:1) was carried out in conventional tight contact mode by mixing soot and catalyst in an agate mortar for ten minutes. This sample was compared with additional samples where the contact between carbon and catalyst was achieved by high-energy milling; the two components were milled in a high-energy mill using $\mathrm{ZrO}_{2}$ vials and balls. The milling time was set from 10 minutes to $8 \mathrm{~h}$. The X-ray diffraction (XRD) profiles of the milled samples do not show any significant modification of the ceriazirconia structure and all samples can be indexed in a fluorite cubic cell (see Figure S2 and Table S1 in the Supporting Information). Textural properties indicate that milling causes 
Table 1: Characteristics and activity data of $\mathrm{Ce}_{0.8} \mathrm{Zr}_{0.2} \mathrm{O}_{2}$ / soot $(\mathrm{CZ} / \mathrm{C})$ mixtures.

\begin{tabular}{llllllll}
\hline Sample & $\begin{array}{l}\mathrm{SA}^{[\mathrm{a}]} \\
{\left[\mathrm{m}^{2} \mathrm{~g}^{-1}\right]}\end{array}$ & $\begin{array}{l}\mathrm{PS}^{[\mathrm{b}]} \\
{[\mathrm{nm}]}\end{array}$ & $\begin{array}{l}T_{50}{ }^{[\mathrm{c}]} \\
{\left[{ }^{\circ} \mathrm{C}\right]}\end{array}$ & $\begin{array}{l}T_{\mathrm{ml}} / T_{\mathrm{m} 2}{ }^{[\mathrm{c}]} \\
{\left[{ }^{\circ} \mathrm{C}\right]}\end{array}$ & $\begin{array}{l}\text { Reaction rate }{ }^{[\mathrm{d}]} \\
\left(\text { air) }\left(\mathrm{N}_{2}\right)\right.\end{array}$ & $\begin{array}{l}E_{\mathrm{a}}{ }^{[\mathrm{e}]} \\
\left.[\mathrm{k}) \mathrm{mol}^{-1}\right]\end{array}$ \\
\hline $\mathrm{CZ}$ & 85 & 5 & $/$ & $/$ & $/$ & $/$ & $/$ \\
CZ/C tight & 81 & 5 & 380 & 380 & 9 & n.m. ${ }^{[\mathrm{g}]}$ & n.d. ${ }^{[\mathrm{f}]}$ \\
CZ/C milled 10 m & 75 & 6 & 345 & 354 & 60 & n.m. & 82 \\
CZ/C milled 40 m & 68 & 8 & 326 & $267 / 340$ & 71 & n.m. & 92 \\
CZ/C milled 1 h & 68 & 8 & 319 & $268 / 338$ & 91 & 8 & 81 \\
CZ/C milled 2 h & 57 & 9 & 287 & $263 / 339$ & 155 & 14 & 82 \\
CZ/C milled 4 h & 39 & 10 & 273 & 269 & 322 & 17 & 81 \\
CZ/C milled 8 h & 36 & 11 & 265 & 265 & 515 & 35 & 73 \\
\hline
\end{tabular}

[a] Surface area. [b] Particle size calculated with Scherrer equation. [c] $T_{50}$, temperature at which $50 \%$ of soot weight is lost under working conditions. The $T_{m}$ peak temperature as given by the derivative weight loss function. [d] Reaction rate measured at $200^{\circ} \mathrm{C}$ in air and inert atmosphere $\left(\mu \mathrm{g}_{\text {soot }} / \mathrm{g}_{\text {soot }}{ }^{*} \mathrm{~s}^{*} \mathrm{~m}^{2}\right)$.

[e] Activation energy calculated in the temperature range of $160-200^{\circ} \mathrm{C}$ for reactions carried out in air atmosphere. [f] Not determined. [g] Not measurable (below the detection limit).
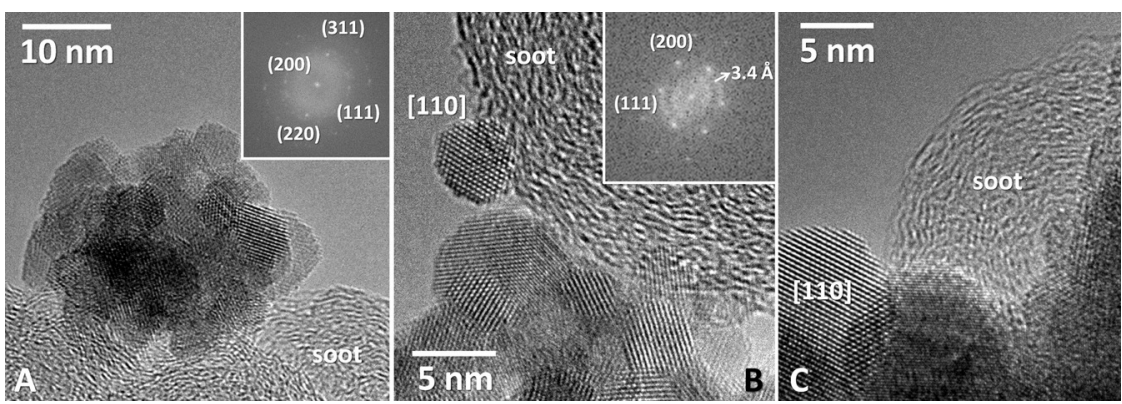

Figure 1. HRTEM images of $\mathrm{Ce}_{0.8} \mathrm{Zr}_{0.2} \mathrm{O}_{2}$ and soot mixed $\mathrm{A}, \mathrm{B}$ ) in tight contact mode (weight ratio catalyst:soot of 20:1) and C) after milling for $1 \mathrm{~h}$. In all cases soot globules (lattice fringes at $3.4 \AA$ ) are identified in contact with crystalline CZ nanoparticles. were no soot clumps and soot has formed a thin layer over the ceria particles in intimate contact (coreshell structure). For example, in the HRTEM image depicted in Figure $2 \mathrm{~B}$ a thin layer of soot is recognized over the ceria crystallites. This soot layer is even more disordered than in the previous samples. Figure 2C displays two ceria-zirconia nanoparticles showing lattice fringes at $3.11 \AA$ corresponding to (111) crystallographic planes of the $\mathrm{CZ}$ lattice. These crystallites are mostly covered by a quasi-monoatomic soot layer, which should be highly reactive.

The presence of a very thin carbon layer is also indirectly supported by the distribution of $\mathrm{Ce}, \mathrm{Zr}$ and carbon atoms on the surface as measured by X-ray photoelectron spectroscopy (XPS) on selected samples (Figure S3). The metal-to-carbon atomic ratio increases with milling time from 0.6 (tight contact) to 1.8 ( $8 \mathrm{~h}$ milling); this is consistent with a progressive substitution of localized large carbon clusters with a thin carbon layer distributed over the surface, which permits the photoemitted electrons from underneath $\mathrm{Ce}$ and $\mathrm{Zr}$ atoms to reach the surface. a partial surface area loss, that is typically observed upon milling of a high-surface-area powder ${ }^{[5]}$ and which is in agreement with an increase of the particle size observed by XRD (Table 1).

The morphology of selected samples before and after milling was investigated by high-resolution transmission electron microscopy (HRTEM). Figure $1 \mathrm{~A}$ shows a HRTEM image of a $\mathrm{Ce}_{0.8} \mathrm{Zr}_{0.2} \mathrm{O}_{2}$ sample and soot mixed under tight contact mode. The oxide nanoparticles are completely crystalline and their sizes range between 4 and $6 \mathrm{~nm}$. The Fourier Transform (FT) image shows rings corresponding to the fluorite planes characteristic of $\mathrm{Ce}_{0.8} \mathrm{Zr}_{0.2} \mathrm{O}_{2}$. Another image is shown in Figure $1 \mathrm{~B}$ for the same sample, where the FT image displays the spots of $\mathrm{CZ}$ as well as wide patches at $3.4 \AA$, which are characteristic of soot. After milling for $1 \mathrm{~h}$, the distribution of the particle size is much broader and shifted towards larger sizes, which is in agreement with powder XRD and Brunauer-EmmettTeller (BET) analysis. In Figure 1 C, large particles of CZ (10$15 \mathrm{~nm}$ ) are visible along with soot globules.

After milling for $4 \mathrm{~h}$, soot aggregates have disappeared to a large extent, and carbon can be observed prevalently as a thin shell over the $\mathrm{CZ}$ crystallites or with a loose morphology (Figure 2A). On the other hand, the size of the $\mathrm{CZ}$ crystallites is considerably larger than in the previous samples, which now ranges from 10 up to $30 \mathrm{~nm}$. After $8 \mathrm{~h}$ milling there
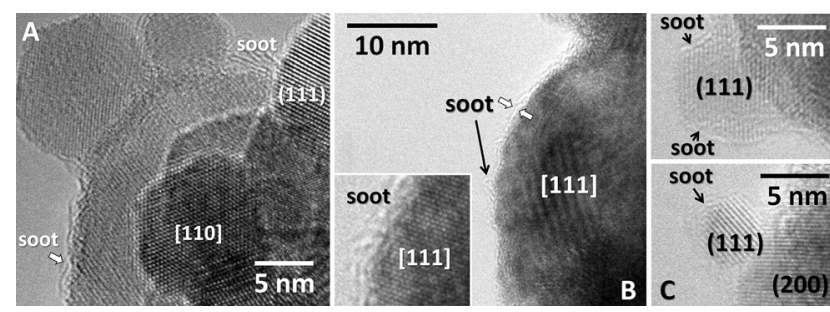

Figure 2. HRTEM images of $\mathrm{Ce}_{0.8} \mathrm{Zr}_{0.2} \mathrm{O}_{2}$ and soot (weight ratio catalyst:soot of 20:1) A) after milling for $4 \mathrm{~h}$ and B, C) $8 \mathrm{~h}$. Soot aggregates have disappeared upon milling and soot is present as a thin shell wrapping the CZ crystallites.

Soot oxidation profiles, as obtained from weight loss curves, are shown in Figure 3 for all samples. The $T_{50}$ and $T_{\mathrm{m}}$ values are reported in Table 1 for comparison. ( $T_{50}$ is the temperature at which $50 \%$ of the soot weight is lost under working conditions and the corresponding derivative function will give the peak temperatures indicated as $T_{\mathrm{m}}$.) For ceriazirconia particles under tight contact conditions the profile is characterized by one single signal in the range of temperatures of $300-450{ }^{\circ} \mathrm{C}$ with a maximum at $380^{\circ} \mathrm{C}$, which is in agreement with previous investigations $;^{[2 \mathrm{~b}, 4,6]}$ prolonged mixing under tight conditions does not modify $T_{\mathrm{m}}$ values. After high-energy milling for 10 minutes, the oxidation 


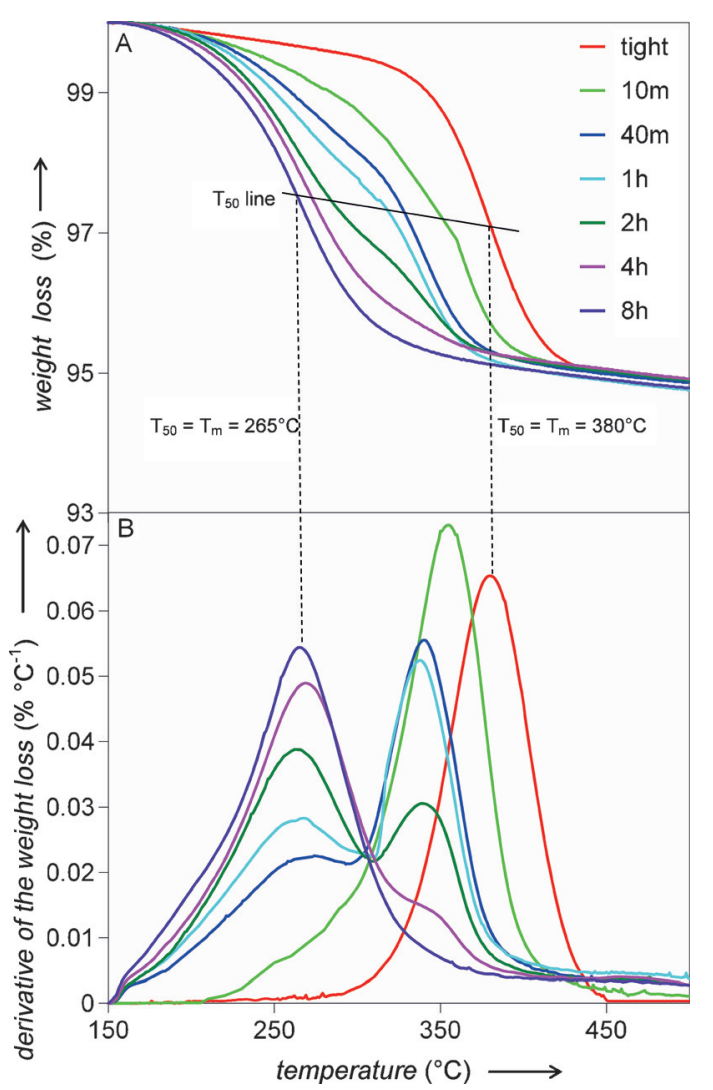

Figure 3. TGA profiles in air of CZ/C mixtures (catalyst:soot ratio of $20: 1)$ treated at different milling time. A) Weight loss curve (\%wt) with indication of the temperature at which $50 \%$ of soot weight is lost under working conditions. B) The corresponding derivative weight loss function with peak profiles because of oxidation. The limit values of $T_{50}$ and $T_{\mathrm{m}}$ measured after 0 (tight) and $8 \mathrm{~h}$ milling are highlighted; all the other values are reported in Table 1.

profile is not modified and the $T_{50}$ value is shifted at lower temperature by 35 degrees. This is likely the result of a more efficient mixing between carbon and catalyst. By increasing the milling time, the oxidation profiles of the samples are strongly altered; they are characterized clearly by a bimodal shape with one component gradually rising at low temperature with increasing milling time $\left(T_{\mathrm{m} 1}\right.$ at ca. $\left.265^{\circ} \mathrm{C}\right)$, which is associated to the oxidation of the carbon layer wrapping the $\mathrm{CZ}$ particles, and the other component with a peak at a high temperature $\left(T_{\mathrm{m} 2}\right.$ at $\left.340^{\circ} \mathrm{C}\right)$, which is related to the oxidation of bigger soot clumps and decreases with increasing milling time.

Remarkably, the oxidation of soot using the sample milled for $8 \mathrm{~h}$, in agreement with its morphology, has one peak only at $T_{50}=T_{\mathrm{m}}=265^{\circ} \mathrm{C}$ and the high-temperature component, typical for the oxidation of soot clumps under tight conditions, has completely disappeared. Similar results are obtained when soot oxidation is carried out under temperature programmed oxidation (TPO) conditions (Figure S4) where the maximum oxidation temperatures are located between 250 and $270^{\circ} \mathrm{C}$ with the onset of oxidation for the most active samples in the range of $50-100^{\circ} \mathrm{C}$. These values are exceptionally lower than those observed for any other soot oxidation catalysts under the same conditions. $\mathrm{CO}_{2}$ is the main oxidation product and only traces of $\mathrm{CO}$ were detected. To confirm the assignments of the two peaks to oxidation of the carbon layer and soot clumps, respectively, a series of HRTEM images were taken over the sample milled for two hours by stopping TPO at increasing temperatures. The results (Figure S5) indicate that the carbon layer is gradually oxidized below $300^{\circ} \mathrm{C}$ and only soot aggregates are found at higher temperatures, slowly vanishing in the range of 300 $450{ }^{\circ} \mathrm{C}$.

Oxidation of soot using catalyst:carbon ratios of 10:1 and 4:1 results in oxidation profiles showing two peaks, even after prolonged milling (Figure S6). This observation is in agreement with the fact that when the amount of carbon exceeds that required to form a thin envelope, the rest will form aggregates that are less prone to oxidation, originating the high-temperature component in addition to the low-temperature peak. The presence of residual soot clumps in these samples is confirmed by HRTEM (Figure S7). A series of samples were also tested where soot and catalyst were individually milled using a high-energy mill and then mixed under conventional tight conditions. The oxidation temperatures in this case do not differ from those observed for conventional tight $\mathrm{CZ} /$ soot samples, indicating that the milling of the single components does not induce any modification in the material that can be responsible for the promotion of the oxidation behavior (Figure S8).

In addition to the $T_{50} / T_{\mathrm{m}}$ values, quantitative measurements of the specific activity under isothermal conditions (both in the presence and absence of oxygen) were also carried out. The results are collected in Table 1 and clearly show that samples prepared by milling have an exceptional specific activity already at $200^{\circ} \mathrm{C}$, a few orders of magnitude higher than that observed for samples prepared under tight conditions. The catalysts are remarkably more active also in the absence of gas-phase oxygen; under these conditions oxidation occurs at the expenses of surface/lattice ceria oxygen and it is measurable already at $200^{\circ} \mathrm{C}$. However, because of the lack of sufficient transferable oxygen, complete soot oxidation cannot be accomplished under these catalyst/carbon loadings. The use of lattice oxygen is also confirmed by monitoring the oxidation state of Ce after the soot oxidation reaction carried out under inert conditions by in situ XPS at $250{ }^{\circ} \mathrm{C}$ (Figure S9). This evidences a $\mathrm{Ce}^{4+}$-to$\mathrm{Ce}^{3+}$ reduction degree of 12 and $24 \%$ for conventional and enhanced contact mode, respectively, which is consistent with a stronger oxygen reverse spillover accelerated when ceria at nanoscale is covered by a carbon envelope. A temperatureprogrammed reaction of soot/catalyst mixtures under inert conditions confirms the above-mentioned findings by showing augmented $\mathrm{CO}_{2}$ evolution in milled sample compared to a conventional sample (Figure S10).

The most accepted mechanism for soot oxidation over ceria in the presence of $\mathrm{O}_{2}$ relies on the formation of active oxygen species by oxygen adsorption on the surface of ceria reduced by soot at the contact points located at the soot/ceria interface. ${ }^{[7]}$ The high-energy milling has the effect of progressively reducing the presence of large $3 \mathrm{D}$ soot clumps and distributing more or less uniformly the carbon over the catalyst by wetting the catalyst surface with an almost $2 \mathrm{D}$ thin 
layer of carbon. The lubricating properties and plasticity of carbon, associated with the different hardness of the two components (0.9-1.3 vs. $4.8 \mathrm{GPa}$ for carbon soot and $\mathrm{CZ}$, respectively) ${ }^{[8]}$ certainly plays an important role in this regard. Under these conditions, the reducing power of carbon coupled with the very high number of contact/ interfacial points promote ceria-zirconia reduction and activate the oxygen path at much lower temperature. In addition to the multiplication and quality of contact points achieved with this methodology, the continuous bond rupture/ formation typical of high-energy milling and the shear and friction forces that ultimately favour an intimate $\mathrm{CZ}$-carbon contact can lead to modification of the shape of the solid solution which causes exposure of more active surfaces that can further promote the oxidation reaction. ${ }^{[9]}$ The presence of defects induced by shear and friction forces is in fact observed with HRTEM in the final composite materials (Figure S7B). The modification of the carbon morphology in contact with ceria-zirconia particles can also contribute to the enhancement of the oxidation rate; as can be seen from Figure S11, the XPS C1s peak broadens when forming the carbon envelope as a consequence of the large structural disorder characterizing different carbon species at the surface strongly interacting with $\mathrm{CZ}$.

In summary, it is shown that the creation of an appropriate catalyst/carbon arrangement at nanoscale enhances by two orders of magnitude the soot oxidation rate and proves that the oxygen of ceria can be transferred and activated at low temperatures of $50-150^{\circ} \mathrm{C}$.

\section{Experimental Section}

Ceria-zirconia particles were prepared by precipitation of an acidic solution of cerium nitrate with $\mathrm{NH}_{4} \mathrm{OH}$ in the presence of $\mathrm{H}_{2} \mathrm{O}_{2}$. The precipitate was dried overnight at $100^{\circ} \mathrm{C}$ and calcined in air at $500{ }^{\circ} \mathrm{C}$ for $3 \mathrm{~h}$. The samples were characterized by X-ray diffraction, $\mathrm{N}_{2}$ adsorption, temperature-programmed reduction, high-resolution transmission electron microscopy, and X-ray photoelectron spectroscopy. Details on the characterization methods are given in the Supporting Information.

Conventional catalyst/soot mixtures were obtained in tight contact mode by mixing the appropriate amount of $\mathrm{Ce}_{0.8} \mathrm{Zr}_{0.2} \mathrm{O}_{2}$ with soot (Printex U by Degussa) in an agate mortar for 10 minutes. Improved contact was achieved in a high-energy Spex mill equipped with nine zirconia balls $(\Phi=10 \mathrm{~mm})$ and a $50 \mathrm{~mL}$ jar. In a typical experiment $1.2 \mathrm{~g}$ of ceria-zirconia particles were milled with $0.06 \mathrm{~g}$ of soot corresponding to a ball-to-powder ratio of 22:1. The milling time was set from 10 minutes to $8 \mathrm{~h}$. The soot oxidation activity was measured in $\mathrm{O}_{2} / \mathrm{N}_{2}$ mixtures by running thermogravimetric analysis (TGA) and TPO experiments. As a measure of activity we used the temperature at which $50 \%$ of soot weight is lost under working conditions $\left(T_{50}\right)$. The corresponding derivative function will give the peak temperatures indicated as $T_{\mathrm{m}}$. Reaction-rate measurements were performed by isothermal experiments at temperatures ranging from $160-200^{\circ} \mathrm{C}$ in air and inert atmosphere as detailed in the Supporting Information.

\section{Acknowledgements}

We are grateful to Regione Friuli Venezia Giulia for support. E.A. thanks financial support from MIUR (Futuro in ricerca, project SOLYST). J.L. is a Serra Húnter Fellow and is grateful to ICREA Academia program and MINECO (grant number ENE2012-36368). L.S. is grateful to Generalitat de Catalunya for a Beatriu de Pinós grant (project number 2013 BP-B 00007).

Keywords: ceria-zirconia particles - heterogeneous catalysis . high-energy milling $\cdot$ oxygen storage $\cdot$ soot combustion

How to cite: Angew. Chem. Int. Ed. 2015, 54, 14040-14043 Angew. Chem. 2015, 127, 14246-14249

[1] A. Bueno-López, Appl. Catal. B 2014, 146, 1-11.

[2] a) E. Aneggi, C. de Leitenburg, J. Llorca, A. Trovarelli, Catal. Today 2012, 197, 119-126; b) I. Atribak, F. E. Lopez-Suarez, A. Bueno-Lopez, A. Garcia-Garcia, Catal. Today 2011, 176, 404408 ; c) L. Katta, P. Sudarsanam, G. Thrimurthulu, B. M. Reddy, Appl. Catal. B 2010, 101, 101-108; d) I. Atribak, B. Azambre, A. B. Lopez, A. Garcia-Garcia, Appl. Catal. B 2009, 92, 126-137; e) C. F. Oliveira, F. A. C. Garcia, D. R. Araujo, J. L. Macedo, S. C. L. Dias, J. A. Dias, Appl. Catal. A 2012, 413, 292-300; f) G. Z. Zhang, Z. Zhao, J. Liu, G. Y. Jiang, A. J. Duan, J. X. Zheng, S. L. Chen, R. X. Zhou, Chem. Commun. 2010, 46, 457459.

[3] a) K. Mudiyanselage, S. D. Senanayake, L. Feria, S. Kundu, A. E. Baber, J. Graciani, A. B. Vidal, S. Agnoli, J. Evans, R. Chang, S. Axnanda, Z. Liu, J. F. Sanz, P. Liu, J. A. Rodriguez, D. J. Stacchiola, Angew. Chem. Int. Ed. 2013, 52, 5101-5105; Angew. Chem. 2013, 125, 5205-5209; b) G. N. Vayssilov, Y. Lykhach, A. Migani, T. Staudt, G. P. Petrova, N. Tsud, T. Skala, A. Bruix, F. Illas, K. C. Prince, V. Matolin, K. M. Neyman, J. Libuda, Nat. Mater. 2011, 10,310-315; c) N. J. Divins, I. Angurell, C. Escudero, V. Perez-Dieste, J. Llorca, Science 2014, 346, 620-623; d) M. Cargnello, V. V. T. Doan-Nguyen, T. R. Gordon, R. E. Diaz, E. A. Stach, R. J. Gorte, P. Fornasiero, C. B. Murray, Science 2013, 341, $771-773$.

[4] E. Aneggi, C. de Leitenburg, A. Trovarelli, Catal. Today 2012, 181, 108-115.

[5] P. Baláz, M. Achimovicová, M. Baláz, P. Billik, Z. CherkezovaZheleva, J. M. Criado, F. Delogu, E. Dutková, E. Gaffet, F. J. Gotor, R. Kumar, I. Mitov, T. Rojac, M. Senna, A. Streletskii, K. Wieczorek-Ciurowa, Chem. Soc. Rev. 2013, 42, 7571-7637.

[6] a) E. Aneggi, C. de Leitenburg, A. Trovarelli, Catalysis by Ceria and Related Materials, Imperial College Press, London, 2013, pp. 565-621; b) Q. Liang, X. D. Wu, X. D. Wu, D. Weng, Catal Lett. 2007, 119, 265-270; c) P. Fang, M.-F. Luo, J.-Q. Lu, S.-Q. Cen, X.-Y. Yan, X.-X. Wang, Thermochim. Acta 2008, 478, 45-50.

[7] E. Aneggi, N. J. Divins, C. de Leitenburg, J. Llorca, A. Trovarelli, J. Catal. 2014, 312, 191-194.

[8] a) D. A. Green, R. Lewis, Proc. Inst. Mech. Eng. Part D 2008, 222, $1669-1689$; b) S. Maschio, O. Sbaizero, S. Meriani, J. Eur. Ceram. Soc. 1992, 9, $127-132$.

[9] a) G. Vilé, S. Colussi, F. Krumeich, A. Trovarelli, J. PérezRamírez, Angew. Chem. Int. Ed. 2014, 53, 12069-12072; Angew. Chem. 2014, 126, 12265-12268; b) E. Aneggi, D. Wiater, C. de Leitenburg, J. Llorca, A. Trovarelli, ACS Catal. 2014, 4, $172-$ 181 .

Received: August 21, 2015

Revised: September 9, 2015

Published online: October 8, 2015 